\title{
The development and current station of marine controlled source electromagnetic transmitter in China
}

\author{
Li Yuan \\ School of Geophysics and information Technology \\ China University of Geosciences (Beijing), CUGB, Beijing \\ Beijing,China \\ athena0071@gmail.com
}

\author{
Wang Lipeng \\ Department of automatic control engineering \\ China Petroleum Engineering Design Co., Ltd. \\ Beijing,China \\ wanglipeng_1987@163.com
}

\begin{abstract}
With the development of modern marine geophysical technology, marine combined source electromagnetic method play an active role in the detectionmethod. Mainly based on the differences of signals detected from substanceunder the sea which with a different electric property, and the signalsare collected by EM induction method. As the distribution of mineral resource in seabed will be known clearly, the huge sea areas have vast resources we need, so the necessity of Marine EM detection should get more attentions. The marine controlled source transmitteris a technology integrated by multi-subjects. Facing such challenge, this paper analyses the theory and design of marine combined source electromagnetic transmitter, and lists some technology index. The aim of this paper is to guarantee the working efficiently and detecting reliability, so a series of high and new technologies should be applied, At last this paper summarizes the current condition of marine combined source magneto telluric receiver and prospect the development tend of this instrument.
\end{abstract}

Keywords- marine electromagnetic; transmitter; key features

\section{INTRODUCTION}

As theabundant resources in sea area in China,where resources under seabed now are detected by different EM induction methods more and more clearly. In geophysical prospecting, EM used to represent the type of EM induction detection methods, detecting the natural electromagnetic fields' signals underground where the substance have different conductivities in different depths. [8]From this we can distinguish the different substances and structures underground.As the environment which is inconsiderable in the deep sea, and the operator processing is extremedifficult, it is necessary to go through a series of experiments following the space of the academic study of marine electromagnetic before.

This paper summarized the related literatures about current developments of domestic and international marine controlled source electromagnetic transmitter. Then introduced the basic principles and newly advanced MSCEM (Marine ControlledSource EM prospecting) methods.[1, 2] Comparing with international development, some influential international sea experiments also are introduced. EM application attracts a growing interest of our marine geophysical scientists.

In recent years, with the development of detecting instruments, data processing and retrieval, interpretation techniques, the reliability and usefulness of this method have been improved a lot. And it provides series basic techniques for Chinese seabed detection.[7]

The technology of detection instruments dominated the marine geophysical development. During the beginning stage of Chinese marine geophysical science, the detection instruments' development plays an important role. And some ofthe pivotal technologies are monopolized by foreign companies. So we still need to improve the technology of detection instrument in the future.

\section{THE CURRENT STATION AND DEVELOPMENT OF THE INTERNATIONAL TRANSIMITTER}

Recent years, controlled source electromagnetics (CSEM) become to be a remote sensing technique, which provides information about subsurface resistivity variations using electromagnetic energy. The method was demonstrated both theoretically and in practice by several calibration and commercial surveys .

In addition, the aim to get the information of the terrain as more as possible through the limited data collection station, now needs the real 3D designer; this means the reasonable designer can not only avoid the disadvantage of the ocean terrain, but also find the most proper position to the detecting position and the excitation position.[5]

The transmitter of the foreign country can operate continuously and reliably for very long periods and without impact on the marine environment. Their frequency spectrums can be optimized to suit local conditions, and they canilluminate hydrocarbon targets through more than $3 \mathrm{~km}$ of rock, regardless of the water depth.Each of the purpose-built 3D EM vessels is equipped with parallel source systems, which includes winches, cranes and hydraulic feeds. This minimizes technical downtime and helps to reduce data delivery times[4].

A horizontal electric dipole EM transmitter for CSEM sounding Output current is up to 500 amps on a neutrally buoyant antenna up to $300 \mathrm{~m}$ long, for a source dipole moment up to $150 \mathrm{~km}$. A combination of acoustic altimeters, long baseline acoustic navigation, depth gauge, and sound velocity meters is used to navigate position.[3] 


\section{THE CURRENT STATION AND DEVELOPMENT OF THE TRANSIMITTER IN DOMESTIC}

Marine electromagnetic detection is an important geophysical method for the study of marine study subject based on distribution of seabed mineral resources.

Magneto telluric regional noise exists, and thus, to suppress interference and quality of the field source data, on the need for data acquisition with a remote reference mode. Inthe acquisition process, including the onshore base station and seabed measuring instrument of the networkshould be followed with a time base and unified position coordinates. Seafloor electromagnetic instruments to meet the above requirements, the interior is equipped with high-precision clock source, gesture detection devices as well as submarine electromagnetic information collected automatically signal measurement and storage circuit.[3]

Operations at sea, the research vessel along predetermined routes, point by point delivery instrument. After the end of the seabed surveys, by remote control to change the nature of the buoyancy of the seabed instrument sothat it automatically returns to the sea. Recent ocean tests showed that the seafloor electromagnetic detection technology has achieved a practical, high-tech support for the marine survey

\section{THE METHOD OF MCSEM}

Marine electrical source towed high-power electromagnetic transmitter is thehardware foundation of the controlled source electromagnetic methods, the controlled source electromagnetic field of the excitation field source, and the hardware block diagram (see Figure 1).

The system is provided by the ship-borne high-power generator electricity, through the transformer deck and monitoring unit and for underwater power and signal transmission cable, power and monitor signal transmission to the seafloor electromagnetic transmitter, and then through thetransmitter internal waveform control circuit and the emission dipole, the electromagnetic waves launched into the media of the seabed.[6]

Deck monitoring unitfor underwater transmitter control signal can be transmitted via the signal cable, easy to view and change the transmitter's operating status. Transmitter through a low-voltage control signal to control the high voltage inverter switches off the inverse of the DC will be added to the transmitter sent out into the desired AC waveform, the inverter AC signal waveform frequency from the deck monitoring unit issued instructions to control.

In addition, the transmitter also includes a towed body, the transmitter pressure capsule, the former line flybar, and emission dipole, altimeter, with a heavy lead weight, watertight connectors and other auxiliary equipment.

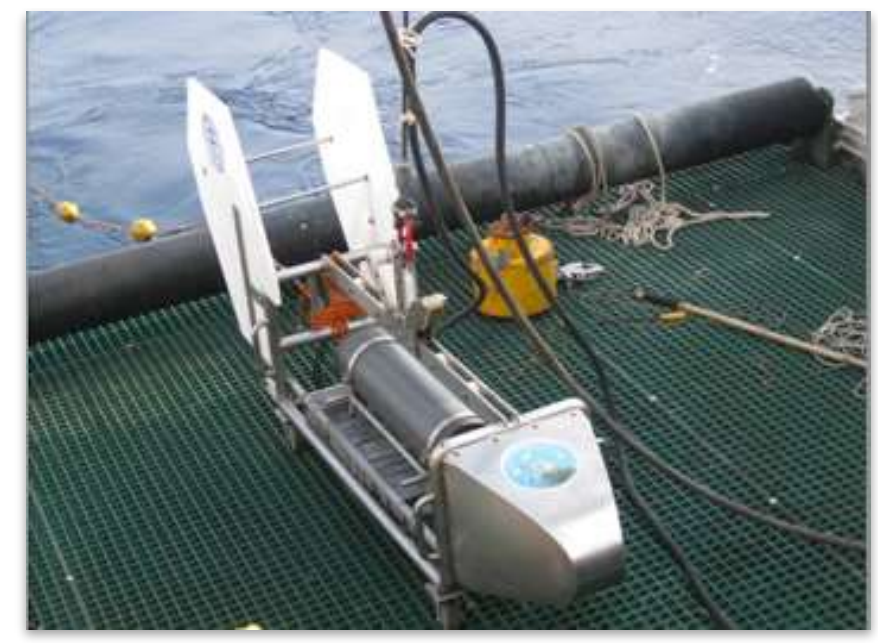

Figure 1. the marine controlled source transmitter in domestic

\section{THE KEY FEATURE OF THE TRANSMITTER}

The primary problem of marine controlled source electromagnetic is the acquisition of signal. To the mature magneto telluric sounding method on land, which has been widely used and the acquisition of technology, the application of this method in the ocean is not an easy way to transplant the problem.

Due to the harsh marine environment, the risk of maritime operations, and weak submarine signal, it is facing numerous difficulties to achieve the seafloor electromagnetic signal acquisition. To achieve the desired detection target requires the use of a series of high-tech, including weak signal detection technology, the seafloor observing systems, high-precision synchronization technology, intelligent control technology, underwater pressure seal technology and hardware system integration technology.[15]

Analysis to detect the technical characteristics of the seabed natural MT raised the seafloor magneto telluricinstrument design. The main problem in the instrument development process: the seabed weak electromagnetic signal detection, submarine measuring network synchronization, undersea environment state monitoring circuit devices of the pressure seal and the entire instrument system of sinking and floating function realization.[16]

Marine towed high-power electrical source electromagnetic transmitter may be a powerful electromagnetic fieldinto the seabed medium, at the same time, the electromagnetic field of the electromagnetic receiver acquisition sensor arranged in the bottom of the sea; during the process of drag, emission of electromagnetic field through thedeep-towed cable to the deck monitoring unit real-time transmission of a variety of underwater equipment status information, with the function of human-computer interaction. [17]

Marine controlled source electromagnetic field measurement, monitoring sea, dragging the body posture informationcan clear dragged the body the process of moving accidents; the position of the record, can be beneficial to the correction of the follow-up track data; high voltage power supply voltage and for the electric current is an indirect 
reflection of the transmitter working properly, forward and reverse supply current is also a follow-up data interpretation process essential parameters; real-time monitoring of the battery pack remaining charge and the internal temperature of the instrument module, the work ofthe monitoring instruments. All the measured information is uploaded to the deck monitoring unit, the operator may at any time on the deck to monitor the operating conditions of the underwater transmitters.(see FIG2)

Marine controlled source electromagnetic is a new attempt ion of electromagnetic methods applied to marine its National exploration of marine resources has important economic significance. Its technical leap in two stages: [9]

(1) The development of marine electromagnetic instrument, made the technological breakthroughs of the seabed electromagnetic signal monitoring means;

(2) To explore the Magneto telluric suitable for China's maritime operations, the magneto telluric method in the futurescale production maritime construction program to develop practical.

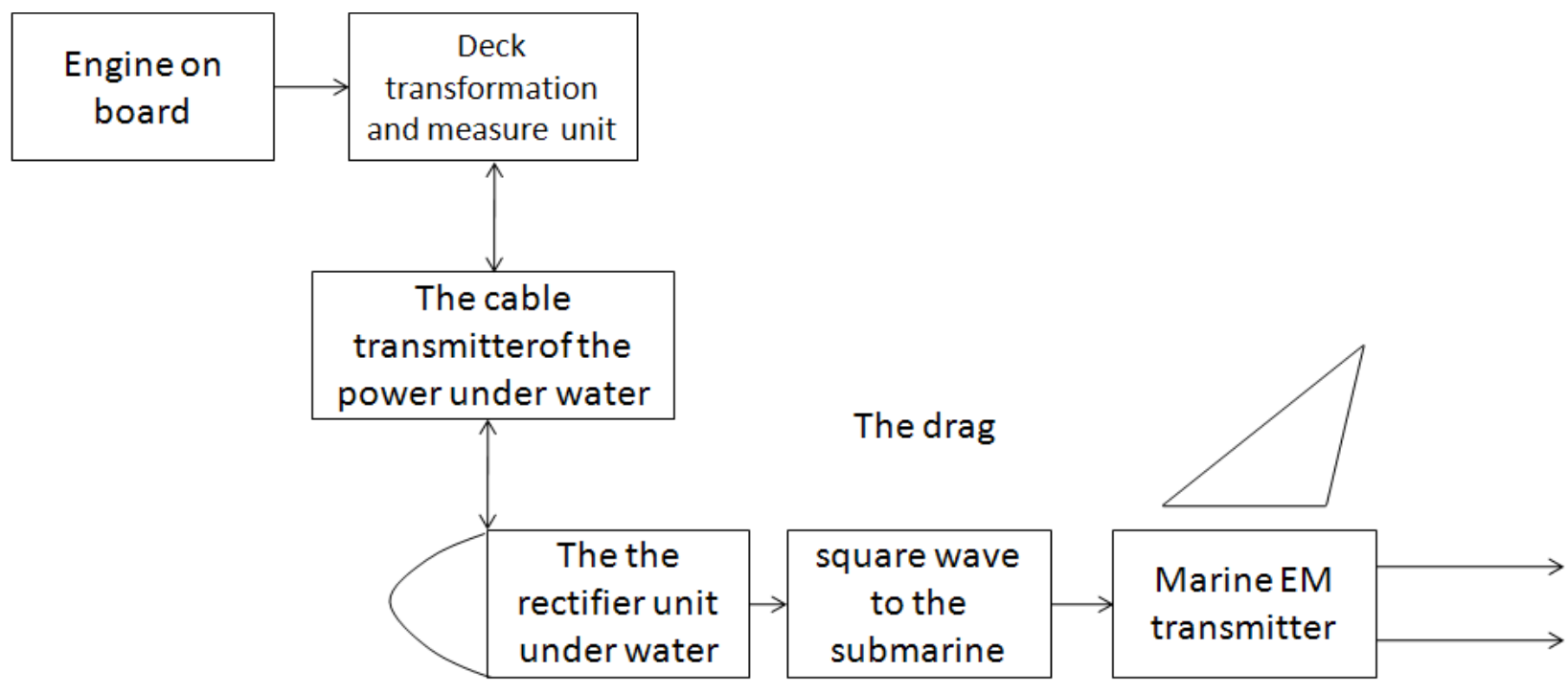

Figure 2. the structure of the transmitter

The index of the transmitter is listing in following [10]:

- The word "data" is plural, not singular.

- the shape of the wave: single square wave;

- the frequency: $(0.1 \sim 100) \mathrm{Hz}$;

- the max transfer current: $100 \mathrm{~A}$;

- the distance of the source: $10000 \mathrm{~A} \cdot \mathrm{m}$;

- the distance of electric source: $100 \mathrm{~m}$;

- the max distance deep in the sea: $4000 \mathrm{~m}$ 。

\section{A. Deep-water apparatus pressure seal technology}

The instrument pressure seal technology for marine controlled source electromagnetic detection hardware premise, especially in deep water conditions of pressure seal technology requirements higher. Only to ensure that the pressure seal in the seabed instrument is required for normal data acquisition[11]

\section{B. the design of high sensitivity, multi-channel signal amplifier}

It is very weak to send and receive signal of natural field source magneto telluric and a little far away from the controlled source signal, so it need to design the high sensitivity of the brightest signal amplifier, in order to meet the needs of the five-component or two-component electromagnetic signals collected. To meet the large dynamic range requirements of the MT signal measurement circuit in addition to lowering their own noise, the choice of Cirrus Logic's high-performance 24-bit AD chip set composed of multi-channel simultaneous sampling ADC[12].

\section{C. the design of the circuit}

The circuit is aimed to design the core emission control system components, including the rectifier unit, control unit and power waveform inverter unit, other hardware, and embedded hardware based on the written driver software. During the underwater transformer rectifier unit converts the output of high-power AC to DC; while control unit, including programmable logic chip and driver board, is aimed to control the waveform inverter power modules, and 
complete the launch of high-power inverter square wave function;[13] Control unit can measure the auxiliary parameters, such as the supply current, supply voltage, the cabin temperature, the dragged body away from the submarine transmitter height, position and posture of the body drag and lithium battery pack remaining charge and other information; With the deep-tow cable of optical fiber, self-developed modules and serial to fiber optic monitoring software deck, the deck-side control unit is used to achieve the remote computer and data communications submarine transmitter. [14]

\section{CONCLUSION}

A set of comprehensive maritime construction program is needed to finish marine controlled source electromagnetic detection. In order to solve the engineering problems encountered in the operation process of the marine environment, such as detection equipment laying the point and the choice of circuit initialization settings, and equipment delivery and recovery, targeted solution: the use of multi-beam scan sonar and grab sampling techniques for seabed topography and sediment; reasonable selection of acquisition parameters according to the bandwidth of the signal; R \& D related to operations at sea dedicated hardware products; voice technology equipment recycling, After the Exploration of the Sea test to verify the validity of the above methods.

\section{Acknowledgment}

This work was supported by"the National 863 Program (2007AA06Z130,2006AA09A201,2009AA09A201)" and "the Key Laboratory of Geo-detection (China University of Geosciences, Beijing), Ministry of Education". I'm grateful to Prof. Deng Ming and my colleagues for their help.

\section{REFERENCES}

[1] A.D. Chave, Constable, S. and Edwards, R.N, Electricalexploration methods for the seafloor. Electromagnetic Methods in Applied Geophysics Society of Exploration Geophysicists, 1991.

[2] R.N. Edwards, Law, L.K., Wolfgram, P.A., Nobes, D.C., Bone, M.N., Trigg, D.F. and DeLaurier, First results of the MOSES experiment: sea sediment conductivity and thickness determination, Bute Inlet, British Columbia, but magnetometric offshore electrical sounding. Geophysics, 1985

[3] S. Ellingsrud, Eidesmo, T., Pedersen, H.M. and Schaug Pettersen,T., Method for electric dipole configuration on the seabed. International patent application, 2002

[4] L.M. and Sinha MacGregor, M.C, Use of marine controlled source electromagnetic sounding for sub-basalt exploration. Geophysical Prospecting, 2000.

[5] L.M. MacGregor, Constable, S.C. and Sinha, M.C., TheRAMESSES experiment - III: Controlled source electromagnetic sounding of the Reykjanes Ridge at $57^{\circ} 45 \notin \mathrm{N}$. Geophysical Journal International 1998.

[6] C. Tan, et al., Synthesis, structures, cellular uptake and apoptosisinducing properties of highly cytotoxic ruthenium-Norharman complexes. Dalton Trans, 2011. 40(34): p. 8611-21.
[7] M.J. Unsworth, Travis, B.J. and Chave, A.D, Electromagnetic induction by a finite electric dipole over a 2-dimensional earth. Geophysics, 1993.

[8] P.D. and Cox Young, C.S., Electromagnetic active source sounding near the East Pacific Rise. Geophysical Research Letters, 1981.

[9] qisheng, z., circuit driver design and hardware realization of acquiring seafloor seafloor enviroment. earth science-journal of china university of geosciences, 2007. ( In Chinese )

[10] meng, w., the technique for memorizing acquisition data doubly and simultaneously on the marine magnetotellurics earth science-journal of china university of geosciences, 2007. ( In Chinese )

[11] ming, d., technique problems in marine geoelectrical field prospecting. instrument technique and sensor 2004. ( In Chinese )

[12] qisheng, z., ciruit drivers of signal-acquiring unit in seafloor magnetotelluric system. progress in geophysics, 2004. ( In Chinese )

[13] ming, d., the marine experiments of seafloor magnetotelluric prospecting. GEOSCIENCE, 2002. ( In Chinese )

[14] ming, d., the putting in and withdrawal of the marine magnetotelluric instruments geosience, 2002. ( In Chinese )

[15] ming, d., real-time casade decimation for seafloor data qcuisition of magnetotelluric field. journal of test and measurement technology, 2008. ( In Chinese )

[16] ming, d., long-span and multi-point synchronizing data acquisiton for seafloor magnetotelluric based on union of marine and land 2006. ( In Chinese )

[17] ming, deng., collector for seafloor magnetotelluric data. china jounal of geophysic, 2003. ( In Chinese ) 